\title{
Message from Mr. Cornelio Sommaruga to mark 8 May, World Red Cross and Red Crescent Day 1987
}

"Our undertaking must be international in scope, for it is universal in nature. It is the task of all for the sake of all; it should be the concern of every human being". These are the words of Henry Dunant, founder of the Red Cross, whose birthday on May 8 is commemorated each year as World Red Cross and Red Crescent Day.

His undertaking has indeed become universal. Today, the International Red Cross and Red Crescent Movement has some 250 million members. May this symbolic date remind us once again of Dunant's humanitarian message!

There are still too many countries where war strikes innocent victims every day, inflicting physical and mental injuries on men, women and children who thus swell the ranks of the wounded, the sick, prisoners and refugees.

Since its creation, the International Committee of the Red Cross has sought to improve the lot of victims of war through law and direct action. The International Committee initiated the Geneva Conventions and remains their champion and guardian. Though almost all of the world's States have by now become party to the Geneva Conventions of 1949 , far fewer have ratified the 1977 Protocols additional to the Geneva Conventions. The work of Henry Dunant must be continued and extended. That is the duty of governments, just as it is the duty of every one of us.

It is within the power of each of us to further the cause of humanity, whether by ratifying a treaty or simply by lending a helping hand to those in need.

But we wish to go beyond respect for the fallen enemy, which is the essence of humanitarian law, and help to create, through the action of the Red Cross, the world of peace to which our humanitarian ideals lead us. Born of war, the Red Cross is Peace. 